\section{BI Report}

\section{Carolyn Kirkendall Projed LOEX}

One of the responsibilities of the bibliographic instruction liaison officer is to target journals in higher education and in specific discipline areas that seem appropriate and accessible for publishing BI-related articles. For specifics on rules for submission of articles in the following general journals. authors may contact me at the address listed below: Academe. Change, Chronicle of Higher Education. College Board Revieu. Educational Record. Improving College and University Teaching. Journal of General Education. and Joumal of Higher Education.

A survey of journals in discipline areas is being conducted by Don Kenney of Virginia Polytechnic Institute. His report on the humanities-related journals identifies 36 journals. ranked according to the possibility of including an article on the instructional role of libraries, out of a total of 1,30 - which he surveyed. Kenney continues to identify journals in the sciences and social sciences arcas with the same goal in mind. and his findings will eventually. be published. His work will be of great help to those who will write on bibliographic instruction and are eager to communicate the teaching service role libraries can provide to faculty and administrators in higher education.

Work on submitting proposals for speeches and presentations by librarians continues. Elaine Jennerich of Baylor University has considered a presentation to be submitted at the Academy of Management for its 43d Annual National Meeting in August. Librarians with advanced degrees in management and business and with $\mathrm{BI}$ experience are encouraged to contact me so that we can build a workable cadre for future proposals.

October will bring us the joint U.S./ Canadian Annual Meeting in Toronto. with its theme. -North American Higher Education: Shaping the Future." A proposal has been submitted for consideration titled, "Integrating Libraries into the Educational Mainstream: The Challenge to Instruct and Support." Word is pending on its acceptance. Participants would be Carolyn Murray. coordinator of user instruction at the Robarts Research $\mathrm{Li}$ brary of the University of Toronto: Joe Boissé. director of Temple University Libraries: and Gerry Meek, coordinator of library instruction at the University of Waterloo.

Your assistance is needed to continue compiling the "press kits" of sample materials. handouts, and research guides to the literature of subject disciplines (described in CLRL News. January 1983). Each folder contains an explanation of our project. material on the role of the library in higher education and on the necessity for Bl service. a short reading list, and sample copies of library-produced handouts.

Disciplines we are currently compiling folders for include sociology: psychology. fine arts. sciences. education, history; political science, and language and literature. W'e would be delighted to

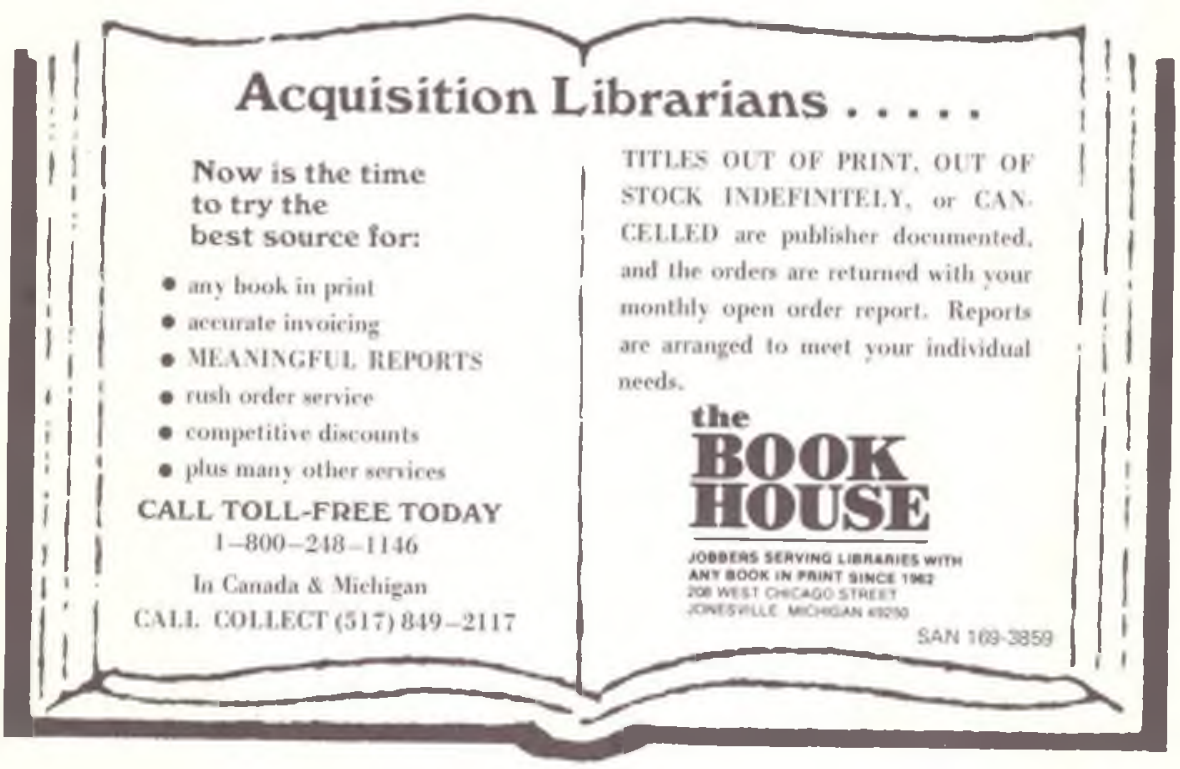


receive your permission and copies of handouts to include in our folders. Your suggestions on pertinent articles from professional journals are also welcome. For a SASE. I will supply samples of reading lists already completed.

The results of contacting the directors of $A R L ~ l i$ braries for suggestions on staff members who have advanced subject degrees and BI expertise have been gratifying. Our project needs to identify those of you who are willing to write proposals and/or participate as a panelist, reactor, moderator, or speaker. We will match the appropriate volunteers with the disciplines and attempt to promote our potential to these associations for their conference agendas.

Our project is based on the conviction that this country's libraries have among their staff members many who would be excellent participants in this project. which furthers our goal of publicizing the instructional role that libraries fill in the mission of our institutions of higher learning.-Carolyn Kirkendall. Director. LOEX Clearinghouse, and ACRL BI Liaison Project Officer. Eastern Michigan University. Ypsilanti, Michigan.

\section{Letter}

\section{Extended Campus Guidelines}

To the Editor:

In the March 1982 issue of CURL. Neus, the ACRL Standards and Accreditation Committee published the "Guidelines for Extended Campus Library Services." After having worked with these guidelines for the past eight months and having had the opportunity to compare their effectiveness to the "Guidelines for Library Services to Extension/Noncampus Students: Draft of Proposed Revisions" (C d RL Neus. October 1980). I can confirm my disappointment. The present guidelines lack the impact that the draft guidelines had: the evalum ative checklist in the draft provided my library with concrete items that were readily presentable to the college administration. Their quantitative measurement of the quality of extended campus library service spoke directly to the administrators on the crucial topics of finances. personnel. facilities, resources, and services.

At a time when state and regional accrediting agencies are scrutinizing more closely extended campus programs. librarians must possess a strong evaluation tool that allows accurate measurements of a program's qualitı, vet is easily understandable to non-librarians. Although the draft guidelines were by no means perfect, they were certainly. pointed in the right direction. The revised guidelines lack the cogency needed by the library profession and program evaluators to judge extended campus library services. - Manuel Sanudo, Extension Services Librarian. College of Neu Rochelle. Neu York.

\section{OCLC COPYRIGHTED}

The OCLC Board of Trustees authorized OCLC management on December 15 to register the OCLC database under federal copyright law. The step " as taken. according to OCLC president Rowland C.W". Brown. as part of a "broad. educational program being undertaken by OCLC and the members to ensure the integrity of the databasc as well as its appropriate and responsible use in keeping with the mutual rights and obligations of its members."

Beginning the week of December 27, 1982. copyright notices have appeared on the online system's log-on message and on various OCLC products derived from the database including OCLC. MARC Subscription Service Tapes, Accession Lists, and Union Lists of Serials. Under the federal copyright law databases are equally entitled to copyright protection whether they are in printed hard copy form or fixed in an electromagnetic medium.

The OCLC Users Council Task Force on Responsible Use of the OCLC Srstem has identified a number of practices by some members and third parties that are detrimental to the continuing value of the database. The Task Force recommended the development of tightened contractual provisions and new pricing mechanisms as a partial remeds:

All contracts now in effect between OCLC and the networks, members. and users will be deemed to include licenses under the copyright as necessary to permit the exercise of all rights granted under such contracts. Other practices not currently authorized either by contract or the fair use doctrine will be considered for licensing by OCLC on terms to be negotiated from case to case including the grant of rovalty-free rights when appropriate.

\section{Index Alert}

Having trouble locating that College \& Research Libraries article on public-academic library cooperation that you read ten vears ago? Looking for a biography of a friend who was profiled in C\&RL Neus? Monitoring the work of an ACRL committee for the past few years?

Your search will be simplified by the Index for Volumes 26 to 40 (1965-1979) of College d Research Libraries and College i- Research Libraries Neuss, prepared by Eldon W. Tamblyn. Many items in CURL Neus which are not indexed anywhere else in library literature appear in this 63-page cumulation, still available from ACRL at $\$ 10$ for ACRL members and $\$ 12$ for non-members. Order from the ACRL office. $50 \mathrm{E}$. Huron Street. Chicago, IL 60611 . Payment must accompany your order. 